\title{
Liberação específica de fármacos para administração no cólon por via oral. I - O cólon como local de liberação de fármacos
}

\author{
Ana Cristina Freire', Fridrun Podczeck², João Sousa', Francisco Veiga ${ }^{1 *}$ \\ ${ }^{1}$ Faculdade de Farmácia, Universidade de Coimbra, Coimbra, Portugal, ${ }^{2}$ Faculdade de Farmácia, Universidade de \\ Sunderland, Reino Unido
}

\footnotetext{
*Correspondência:

F. Veiga

Faculdade de Farmácia de Coimbra

Rua do Norte, 3000

Coimbra - Portugal

E-mail fveiga@ci.uc.pt
}

\begin{abstract}
A liberação específica de fármacos no cólon tem atraído a atenção de investigadores interessados no tratamento de patologias locais e no seu potencial na liberação de proteínas e peptideos. O tratamento de patologias do cólon como é o caso da doença inflamatória do intestino pode ser otimizada com o recurso destes sistemas que se propõem a liberar o agente farmacológico adequado, seletivamente no local ativo de inflamação, na medida em que diminuem a dose oral e os seus efeitos adversos. A atividade das peptidases no cólon é muito baixa, o que torna possível que moléculas tão lábeis como as proteinas e peptídeos possam ser administrados oralmente sem comprometer a sua biodisponibilidade. Para desenvolver estes sistemas éfundamental entender completamente o cólon enquanto local de liberação de fármacos e, em particular, aspetos como o tempo de trânsito, pH e atividade enzimática do cólon que são a base dos mecanismos utilizados para iniciar a liberação de fármacos no cólon. Outro aspecto importante é a capacidade de absorção do cólon. Neste contexto, o extenso tempo de residência e a presença de barreiras químicas e biológicas podem, respectivamente, aumentar ou limitar a absorção de fármacos. O impacto da doença inflamatória do intestino na eficácia destes sistemas pode ter sido subestimado, na medida em que esta patologia pode alterar o pH e a actividade enzimática do cólon.
\end{abstract}

\author{
Unitermos \\ - Cólon \\ - Trânsito gastrointestinal \\ - pH do cólon \\ - Microflora do cólon \\ - Absorção \\ - Doença inflamatória do \\ intestino
}

\section{INTRODUÇÃO}

Nos últimos anos, assistiu-se a um crescente interesse no desenvolvimento de sistemas de liberação específica de fármacos por via oral. O objetivo destes sistemas é promover a liberação de fármacos especificamente em determinadas regiões do trato gastrointestinal, como é o caso do cólon.
Até há pouco tempo, o cólon era considerado como um local de reabsorção de água e fermentação de carboidratos residuais, mas atualmente é encarado como um local ativo de absorção de fármacos (Sinha, Kumria, 2002) com indiscutíveis vantagens terapêuticas (Ashford, Fell, 1994; Van Der Bilj, Eyk, 2003). Uma dessas vantagens diz respeito à administração oral de proteínas e peptídeos que, como é sabido, são alvo de intensa degra- 
dação enzimática no intestino delgado, o que lhes confere uma biodisponibilidade oral muito baixa (Rubinstein et al., 1997). O cólon apresenta um elevado potencial para acolher formulações orais de proteínas e peptídeos, pois oferece um ambiente menos hostil devido a uma menor diversidade e intensidade da atividade enzimática e a um pH quase neutro (Ashford, Fell, 1994; Gupta et al, 2001).

A liberação específica de fármacos no cólon pode, ainda, ser útil em cronofarmacoterapia. É do conhecimento geral, que a sintomatologia de um extenso número de patologias, bem como a farmacocinética e farmacodinâmica de alguns fármacos são alvo de ritmos temporais, que muitas vezes resultam em variações circadianas (Sangalli et al., 2001). São exemplos algumas patologias como a asma bronquial, angina pectoris e artrite reumatóide (Sawada et al., 2004). Neste contexto, a liberação específica de fármacos no cólon pode configurar uma alternativa valiosa ao possibilitar um atraso na absorção ou uma maior concentração plasmática no momento do ciclo circadiano em que os sintomas clínicos se desenvolvem ou estão na sua máxima expressão (Ashford, Fell, 1994; Sawada et al., 2004).

Uma das maiores aplicações dos sistemas de liberação específica no cólon consiste no tratamento local de patologias do cólon como a doença inflamatória do intestino, algumas infecções, diarréia, obstipação ou carcinomas colorrectais (Ashford, Fell, 1994; Van Der Mooter, Kinget, 1995; Khan, Prebeg, Kurjakovic, 1999). Até ao momento, o tratamento destas doenças é difícil quer pela via oral, quer pela via rectal que no caso desta última ser pouco aceite por parte do paciente e raramente é eficaz na liberação de fármacos no cólon ascendente (Steed, Wilson, Washington, 1989; Ashford, Fell, 1994).

A doença inflamatória do intestino consiste numa inflamação localizada do intestino delgado e cólon. Uma vez que a inflamação está confinada a locais específicos da mucosa intestinal, é vantajoso liberar especificamente os fármacos no local ativo da doença, reduzindo a dose total de fármaco administrada e, consequentemente, uma menor expressão dos efeitos secundários atribuídos a algumas terapêuticas farmacológicas (Klotz, Schwab, 2004). Como se trata de uma doença crónica, é conseguida ainda, uma melhor adesão à terapêutica.

Vários sistemas de liberação específica de fármacos no cólon têm sido propostos quer no âmbito do tratamento local de patologias quer com vista à absorção sistémica de fármacos. Alguns deles encontram-se comercializados, outros não passam de meras hipóteses tecnológicas. Na perspetiva de desenvolvimento destes sistemas é vantajoso conhecer as caraterísticas anatomofisiológicas, capacidade de absorção e patologi- as do cólon não esquecendo, porém, que existe uma elevada variabilidade interindividual na fisiologia (tempo de trânsito gastrointestinal e perfis de $\mathrm{pH}$ ), padrão da doença e disposição de fármacos.

O objetivo desta revisão é analisar o cólon como potencial local de liberação de fármacos.

\section{CARACTERIZAÇÃO ANATOMOFISIOLÓGICA DO CÓLON}

O cólon humano é a porção final do trato gastrointestinal (Fig.1). É um órgão complexo constituído pelo cólon ascendente (ou cólon direito), cólon transverso, cólon descendente ou esquerdo e o cólon sigmóide, ao qual se encontra ligado o recto e o ânus. $\mathrm{O}$ apêndice é um segmento com a forma de um dedo que sai do cólon ascendente perto do ponto onde este se une ao intestino delgado (cego). Entre o intestino delgado e o grosso existe um estreitamento designado de válvula ileocecal, cujas funções incluem a regulação do movimento do conteúdo intestinal entre estas duas regiões e a prevenção do refluxo do conteúdo do cólon, incluindo bactérias.

Nos adultos, este órgão apresenta um comprimento de 1,5 metros, 6,5 centímetros de diâmetro e uma área total de $0,3 \mathrm{~m}^{2}$ (Faigle, 1993). Contrariamente, a área total do intestino delgado é de cerca de $120 \mathrm{~m}^{2}$, o que vai ao encontro das funções de digestão e absorção que ocorrem maioritariamente neste local.

Histologicamente, a parede do cólon é formada por quatro camadas. Da mais externa para a mais interna designam-se respetivamente, por camada serosa, muscular externa, submucosa e mucosa. A mucosa do cólon é composta pela mucosa muscular, a lâmina própria e o epitélio. A lâmina própria possui grande quantidade de vasos sanguíneos e linfáticos e de células sanguíneas (por exemplo, linfócitos e macrófagos) importantes na função imunológica do cólon.

Estas camadas são formadas por células designadas de enterócitos que se encontram intimamente ligadas, constituindo uma barreira a transpôr entre o lúmen do cólon e a circulação sanguínea.

O cólon e porção superior do recto são irrigados pelas artérias mesentéricas superior e inferior, pelo que qualquer fármaco absorvido nesta região é directamente encaminhado para o fígado onde será sujeito ao efeito de primeira passagem. Os fármacos absorvidos pela porção inferior do recto e canal anal são transportados pela veia cava evitando o intenso metabolismo hepático (Steed, Wilson, Washington, 1989).

A inervação do cólon é feita quer pelo sistema nervoso simpático, quer pelo sistema nervoso parassimpático, 
com domínio do primeiro, que é responsável pela manutenção de uma inibição da atividade motora (Edwards, 1993). A estimulação dos nervos parassimpáticos produz um aumento da contratibilidade motora, da secreção de muco e uma vasodilatação local.

Os padrões de motilidade das várias regiões do cólon são distintos e só assim faz sentido que lhe sejam atribuídas, simultaneamente, acções de fermentação, propulsão e reservatório do conteúdo fecal (Edwards, 1993). Assim, a primeira porção do cólon, que compreende o cego, cólon ascendente e parte do cólon transverso, caracteriza-se por um anti-peristaltismo, pelo que o conteúdo fecal é aí retido por longos períodos de tempo, o que irá permitir uma absorção prolongada de água, electrólitos e princípios activos, se estes forem passíveis de ser absorvidos nesta região. Além disso, nesta porção o conteúdo intestinal não é tão viscoso, o que faz do cólon proximal o local preferencial de liberação de fármacos (Macleod, Tozer, 1992; Peteers, Kinget, 1993; Ashford, Fell, 1994). A restante parte do cólon transverso e cólon descendente são caracterizados por movimentos peristálticos coordenados que forçam o conteúdo intestinal a fragmentar-se e progredir em direcção à porção final do cólon.

O cólon sigmóide e recto armazenam as fezes e apresentam um arco reflexo de defecação e como tal esta zona é caracterizada por contrações musculares vigorosas.

O cólon é responsável pela absorção de água e electrólitos: absorve sódio e cloro e secreta os ions bicarbonato e potássio (Edwards, 1993).

As suas outras funções incluem a secreção de muco que protege a parede do cólon dos danos que o material fecal pode causar; da fermentação exercida pela microflora intestinal de alguns compostos (sobretudo hidratos de carbono não absorvidos nas porções superiores do tracto gastrointestinal) e, por último, transformação do conteúdo intestinal em fezes.

\section{TEMPO DE TRÂNSITO GASTROINTESTINAL}

É pretensão de qualquer sistema de liberação específica no cólon, que seja mínima ou mesmo nula a absorção de fármaco através da mucosa gástrica e do intestino delgado, e máxima no cólon. A absorção de fármacos, por sua vez, é função do tempo de contacto destes com as mucosas, pelo que pode ser estimada através do estudo dos tempos de trânsito gastrointestinal.

Para obter uma absorção máxima no cólon, o tempo de residência nesta região deve ser considerado. Neste sentido, um tempo de trânsito demasiado rápido diminui o tempo necessário para que ocorra desagregação da forma farmacêutica e absorção no cólon.
No entanto, antes de atingir o cólon a forma farmacêutica deve atravessar o estômago e o intestino delgado, o que pode constituir um risco. Na realidade, um tempo de esvaziamento gástrico e/ou tempo de trânsito no intestino delgado elevados podem resultar numa elevada absorção do fármaco nestas regiões e, consequentemente, comprometer a biodisponibilidade e a eficácia de alguns sistemas de liberação específica no cólon.

Nesta secção faz-se uma revisão dos tempos de trânsito em cada região do tracto gastrointestinal, com especial ênfase nos tempos de trânsito de formas farmacêuticas e dos métodos disponíveis para a sua determinação.

\section{Métodos de avaliação do tempo de trânsito gastrointestinal - o papel da ${ }^{3}$-cintilografia}

O tempo de trânsito gastrointestinal pode ser avaliado através de métodos invasivos ou diretos (como é o caso da endoscopia), ou recorrendo a métodos não invasivos. Presentemente, os métodos não invasivos são os mais utilizados pois oferecem a vantagem óbvia de não perturbar os processos fisiológicos normais e, de um modo geral, serem menos dolorosos para o paciente.

Dentro dos métodos não invasivos, $\mathrm{a}^{3}$-cintilografia assume-se, cada vez mais, como a técnica de eleição na monitorização dos tempos de trânsito através do trato gastrointestinal de alimentos ou formas farmacêuticas (Hardy, 1993). Não obstante, durante vários anos esta avaliação passou pelo uso de outras técnicas como a administração oral de uma determinada forma farmacêutica tornada opaca pela inclusão, por exemplo, de sulfato de bário seguida da sua localização recorrendo a radiografias (Follonier, Doelker, 1992). Atualmente, o uso desta técnica é considerado pouco ético na medida que resulta numa exposição do paciente a elevadas doses de radioatividade.

Outro método não invasivo de avaliação do tempo de trânsito gastrointestinal consiste na medição da concentração de hidrogênio no ar expirado. Este método, extremamente fácil de executar, baseia-se no princípio de que os carboidratos, que não são absorvidos no intestino delgado, sofrem fermentação pelas bactérias do cólon resultando em hidrogênio gasoso que pode ser detectado no ar expirado (Hardy, 1989; Read et al., 1989).

$\mathrm{A}^{3}$-cintilografria permite-nos adquirir informações sob condições fisiológicas normais ou na presença de alterações patológicas (Hardy, 1989; Hardy, 1993; Wilding, 1995). Esta técnica envolve, basicamente, a marcação de um composto com um radionuclídeo que emite radiações gama permitindo, assim, o seu acompanhamento exterior através do uso de uma câmara gama (Adkin et al., 1993). 
Normalmente, o radionuclídeo é absorvido num composto inerte, não absorvido pelo trato gastrointestinal e posteriormente adicionado ao núcleo da forma farmacêutica da qual constam entre outros compostos o príncipio ativo. Desta forma, esta técnica é considerada segura dado que não resulta na absorção de compostos radioativos. Por outro lado, dado que as quantidades de radionuclídeo requeridas são muito baixas, não afetam as propriedades da forma farmacêutica ou o trânsito gastrointestinal da mesma (Follonier, Doelker, 1992). Como principal desvantagem deve salientar-se o fato da ${ }^{3}$ cintilografia não fornecer informações sobre a anatomia do trato digestivo.

As vantagens atrás descritas têm sido intensamente exploradas em várias investigações (Hardy, Wilson, Wood, 1985; Hardy et al., 1988; Hardy, 1989; Hardy, 1993; Steed et al., 1994; Wilding, 1995) com a finalidade de estudar os tempos de esvaziamento gástrico, trânsito de formas farmacêuticas no intestino delgado e cólon, absorção de fármacos, avaliação do comportamento de sistemas de liberação controlada, avaliação da eficácia de fármacos destinados a promover um aumento ou redução do tempo de trânsito dos alimentos e, ainda, a monitorização dos tempos de trânsito gastrointestinal em pacientes com diarreia, obstipação, doença de Crohn ou colite ulcerosa.

Através desta técnica, podem ser obtidas as seguintes informações acerca da comportamento de um sistema de liberação específica no cólon: localização em função do tempo decorrido; momento e local de desintegração inicial e completa do sistema; extensão da dispersão; momento da chegada ao cólon e tempo de permanência no estômago e no intestino delgado (Yang, Chu, Fix, 2002).

\section{Tempo de esvaziamento gástrico}

O tempo de permanência de formas farmacêuticas e alimentos no estômago é altamente variável inter e intraindividualmente e dependente de vários fatores. Esses fatores podem ser de natureza fisiológica, patológica ou farmacológica. Entre os primeiros, encontramos o volume da refeição, a sua natureza (o esvaziamento é mais lento no caso de refeições ricas em proteínas e/ou lípidos), o conteúdo energético (refeições altamente energéticas demoram mais tempo a abandonar o estômago), acidez (a velocidade de esvaziamento é máxima para valores de $\mathrm{pH}$ entre 3,5 e 5), viscosidade (quanto maior a viscosidade, mais lento o tempo de esvaziamento) e temperatura, sendo que a passagem através do estômago é mais rápida no caso de líquidos frios. Para além disso, fatores diretamente relacionados com o indivíduo tais como o exercício físico, posição em que se encontra, idade e fatores de ordem emocional podem ter um efeito direto no tempo de esvaziamento gástrico.

Determinadas patologias como a diabetes, úlceras gástricas e refluxo gastroesofágico aceleram o tempo de esvaziamento gástrico, ao passo que outras como o hipertiroidismo ou úlcera doudenal tendem a diminui-lo (Riley, 1993). Por último, relativamente ao impacto de fármacos, a domperidona e os opiáceos, são exemplos de substâncias que, respetivamente, aceleram e diminuem o tempo de esvaziamento gástrico. Contudo, os fatores mais determinantes no que respeita ao esvaziamento gástrico de formas farmacêuticas são o seu tamanho, densidade e a ingestão de alimentos.

A apreciação do papel da ingestão de alimentos no tempo de esvaziamento gástrico requer uma explicação sucinta dos padrões de motilidade do estômago.

$\mathrm{Na}$ ausência de alimentos o estômago encontra-se sob o controle do complexo motor migratório, que consiste em ciclos compostos por quatro fases consecutivas (Ashford, Fell, 1994; Goto et al., 2004). As contrações peristálticas mais vigorosas ocorrem na fase III desse complexo as quais conduzem à abertura do esfincter pilórico e consequente esvaziamento gástrico. Este ciclo repete-se em cada duas horas, pelo que o esvaziamento de uma forma farmacêutica nestas circunstâncias, pode demorar apenas alguns minutos ou cerca de 2 horas, dependendo do momento em que a sua administração é feita em relação à fase III do dito complexo.

Durante uma refeição, o complexo motor migratório é substituído por movimentos peristálticos que aparecem 5 a 10 minutos após a ingestão e permanecem enquanto existirem alimentos no estômago (Ashford, Fell, 1994; Follonier, Doelker, 1992). Neste contexto, a evacuação de formas farmacêuticas ocorre, apenas, após completa digestão e sob a ação da fase III do complexo motor migratório.

O efeito da presença de alimentos no tempo de esvaziamento gástrico foi intensamente discutido por vários investigadores nas últimas duas décadas (O'Reilly, Wilson, Hardy, 1987; Davis, Hardy, Fara, 1986; Kyroudis, Markantonis, Beckett, 1988; Borin et al, 1990). Um desses primeiros estudos (O' Reilly, Wilson e Hardy, 1987) comparou o esvaziamento gástrico de sistemas multiparticulados antes e depois de uma refeição. Os resultados demonstraram um esvaziamento gástrico exponencial na ausência de alimentos e linear na presença destes. O comportamento verificado na ausência de alimentos corresponde ao padrão típico de esvaziamento gástrico de líquidos. A composição da refeição também demonstrou influenciar em grande extensão os tempos de esvaziamento gástrico: um aumento do valor calórico de uma refeição 
resultou num considerável atraso no esvaziamento gástrico quer de formulações líquidas quer de formulações sólidas (Christian et al., 1980).

Outros parâmetros importantes são o tamanho das formas farmacêuticas e a sua densidade.

Alguns investigadores são da opinião que partículas de menores dimensões (formas farmacêuticas como os peletes) à semelhança dos compostos líquidos, podem ser continuamente evacuadas através do esfíncter pilórico na fase pósprandeal, e como tal são pouco afectadas pela ingestão de alimentos (Davis, Hardy, Fara, 1986; Deveroux, Newton, Short, 1990). Este aspecto, contudo, não é consensual. Alguns estudos apontam para um ligeiro atraso no esvaziamento gástrico de sistemas multiparticulados após administração concomitante de alimentos (Kyroudis, Markantonis, Beckett, 1988), evidenciando que a variabilidade nos tempos de esvaziamento gástrico existe e depende quer do estado de nutrição quer da forma farmacêutica. No entanto, é mais prevísivel e menos extensa no caso de sistemas multiparticulados (Davis, Hardy, Fara, 1986).

Com base nisto, o recurso a formas farmacêuticas como os peletes ou as microsferas tem-se assumido cada vez mais como uma alternativa viável para eliminar a variabilidade nos tempos de esvaziamento gástrico. Vários estudos (Sugito et al, 1992; Clarke, Newton, Short, 1993) foram conduzidos em modelos animais e em humanos, por forma a encontrar o tamanho crítico, abaixo do qual as formas farmacêuticas exibiam um comportamento mais previsível nos seus tempos de esvaziamento gástrico. Apesar de alguns valores terem sido referidos, a variabilidade intra e interindividual dos tempos de esvaziamento gástrico, bem como as limitações da extrapolação dos resultados em modelos animais para o Homem, leva-nos a ser cautelosos na interpretação desses resultados. Sabe-se, apenas, que a previsibilidade do esvaziamento gástrico diminui à medida que se aumenta o tamanho das formas farmacêuticas e que partículas com dimensões superiores a $10 \mathrm{~mm}$ são retidas no estômago (Follonier, Doelker, 1992).

$O$ efeito da densidade das formas farmacêuticas oferece, ainda, mais controvérsia. Alguns investigadores (Deveroux, Newton, Short, 1990; Tuleo et al., 1999) são da opinião que quanto maior a densidade de uma dada partícula, maior o seu tempo de retenção gástrico, presumivelmente devido à capacidade que estas partículas apresentam para se posicionar na parte inferior do antro do estômago. Na realidade, a modificação da densidade de formas farmacêuticas é uma estratégia que tem sido adotada no sentido de prolongar a permanência no estômago de fármacos predominantemente absorvidos nas regiões superiores do trato gastrointestinal ou de fármacos praticamente insolúveis nos fluídos intestinais como é o caso do Diazepam (Rouge, Buri, Doelker, 1996). No entanto, alguns estudos (Bechgaard et al., 1985; Clarke, Newton, Short, 1995) levam-nos a crer que o tempo de esvaziamento gástrico de formas farmacêuticas não é significativamente afetado pela densidade.

\section{Tempo de trânsito no intestino delgado}

À semelhança do estômago, o intestino delgado exibe diferentes padrões de motilidade em função da presença ou ausência de alimentos. Durante a fase pósprandeal, o intestino delgado é dominado por movimentos peristálticos que asseguram a mistura e propulsão do seu conteúdo, e que uma vez terminada dá lugar ao complexo motor migratório.

Por oposição ao tempo de esvaziamento gástrico, o tempo de trânsito no intestino delgado é relativamente constante, sendo de aproximadamente $3 \pm 1$ horas (Davis, Hardy e Fara, 1986) e não é afetado pelo estado de nutrição ou pela natureza da refeição.

Além disso, o intestino delgado parece não distinguir entre líquidos e sólidos, nem discriminar sólidos de diferentes dimensões ou densidades, pelo que o tempo de trânsito nesta região é independente da forma farmacêutica (Davis, Hardy, Fara, 1986; Riley, 1993).

\section{Trânsito através da válvula ileocecal}

A válvula ileocecal apresenta um padrão de motilidade distinto do intestino delgado e estômago e com implicações evidentes ao nível do trânsito de formas farmacêuticas nesta região. O trânsito através desta válvula é independente do complexo motor migratório que raramente atinge o íleo distal, mas parece estar relacionado com a velocidade de acumulação do conteúdo intestinal nesta região (Quigley et al., 1984) que por sua vez depende do estado de nutrição. Spiller et al. (1987) verificaram que 2,5 horas após a ingestão de alimentos o trânsito na válvula ileocecal é regular e rápido, enquanto na ausência destes se revela lento e errático.

Num estudo realizado em oito voluntários saudáveis (Adkin et al., 1993), do sexo masculino, avaliou-se o tempo de trânsito gastrointestinal de comprimidos com diferentes tamanhos $(3,9$ e $12 \mathrm{~mm})$ recorrendo à técnica de ${ }^{3}$ cintilografia. Dada a ação de "válvula" seria de esperar que formas farmacêuticas de maiores dimensões como os comprimidos, ficassem retidos na junção ileocecal por longos períodos de tempo. No entanto, o trânsito mostrouse independente do tamanho dos comprimidos no intervalo estudado, sendo que todos eles entraram no cólon como 
um bolus após um período de retenção compreendido entre 0 e 99 minutos.

O reagrupamento de formas farmacêuticas nesta válvula tem sido mencionado em vários artigos (Phillips et al., 1988; Davis, 1989; Abrahamsson et al., 1996) como sendo um fenómeno sujeito a elevada variabilidade e que parece não estar relacionado com a forma farmacêutica, padrões de motilidade intestinal (Quigley et al., 1984) ou pela natureza dos alimentos ingeridos (Price et al., 1993).

\section{Tempo de residência no cólon}

A progressão de formas farmacêuticas e outros materiais no cólon não é um processo contínuo e normalmente consiste em períodos de trânsito rápido separados por várias horas de pouca ou nenhuma progressão (Davis, Hardy, Fara, 1986; Hardy et al., 1989; Follonier, Doelker, 1992).

Este padrão de motilidade peculiar, resulta em tempos de residência do conteúdo intestinal no cólon muitos elevados, sendo em condições fisiológicas normais sempre superior ao tempo que este demora a percorrer as restantes regiões do trato gastrointestinal. Em indivíduos normais, o tempo de trânsito de alimentos na região proximal situa-se, aproximadamente, entre as 7 e as 11 horas. No cólon esquerdo é de cerca de 9 a 11 horas e por último no cólon sigmóide, varia entre as 12,5 e 18,5 horas (Metcalf et al., 1987; Mrsny, 1992a). Deste modo, o tempo de trânsito total é de cerca de 22-36 horas, podendo variar entre 18 e 144 horas (Edwards, 1993).

O trânsito no cólon é afetado por vários fatores como as caraterísticas da dieta (Gear et al., 1981), patologias, stress (Enck et al., 1989), medicação e sexo. Por exemplo, o tempo de trânsito é superior nas mulheres, em particular ao nível do cólon proximal (Metcalf et al., 1987; Edwards, 1993) e encontra-se acelerado em condições de stress. Algumas patologias podem aumentar ou diminuir o tempo de residência no cólon como é o exemplo, respectivamente da obstipação e diarreia. Estas patologias, por sua vez, são efeitos secundários de algumas terapêuticas farmacológicas, que nesse caso, podem igualmente contribuir para estados de motilidade colónica anormais.

O efeito mais preponderante é a dieta: uma dieta rica em fibras parece acelerar o tempo de trânsito no cólon possivelmente por um mecanismo de distensão da parede provocado por algumas fibras com elevada capacidade de retenção de água (Gear et al., 1981).

O trânsito de formas farmacêuticas no cólon tem sido extensamente estudado (Hardy, Wilson, Wood, 1985; Davis, Hardy, Fara, 1986; Macleod, Tozer, 1992; Hardy, 1993). Os resultados desses estudos evidenciaram uma elevada variabilidade interindividual, com tempos de trânsito variando entre 1 hora e 60 horas (Hardy, 1989).

Hardy et al. (1985) compararam o tempo de trânsito gastrointestinal de cápsulas e peletes e verificaram que ambas formas farmacêuticas atravessaram simultaneamente o estômago e intestino delgado, atingindo o cólon 4 horas após a administração. No entanto, os peletes exibiram um tempo de trânsito no cólon mais longo.

Estes resultados foram confirmados posteriormente por estudos similares (Adkin et al., 1993; Abrahamsson et al., 1996) demonstrando que o trânsito no cólon é dependente da forma farmacêutica, isto é, comprimidos e cápsulas passam mais rapidamente pelo cólon do que soluções e peletes. Este fenómeno ocorre aparentemente porque o cólon, em condições fisiológicas, reconhece as formas farmacêuticas sólidas de maiores dimensões, como sendo material não digerível. Este fenómeno causa uma alteração dos padrões normais de motilidade, provocando um tempo de trânsito mais rápido no caso de comprimidos. Contrariamente, as formas farmacêuticas líquidas e peletes correspondem a material passível de sofrer digestão, pelo que o seu trânsito no cólon é mais lento (Goto et al., 2004).

Além do tipo de forma farmacêutica, a ingestão de alimentos também altera o movimento de partículas no cólon. Este fenómeno, denominado de resposta gastrocolónica, caracteriza-se por um aumento da motilidade do cólon resultante da ingestão de alimentos, provocando, em última instância uma diminuição do tempo de trânsito nesta região.

O efeito da composição de uma refeição na resposta gastrocolónica e as suas implicações para a liberação de fármacos no cólon foi estudado por Price et al. (1993). Oito indivíduos do sexo masculino receberam comprimidos marcados radioactivamente e o seu trânsito foi seguido através de ${ }^{3}$-cintilografia. Quando os comprimidos chegaram à válvula ileocecal, todos os indivíduos receberam refeições com diferentes composições. A ingestão de alimentos provocou uma aceleração do movimento dos comprimidos através da válvula ileocecal. No entanto, aparentemente, não existe nenhuma influência por parte da composição da refeição no trânsito de comprimidos ao longo do cólon.

Para concluir, a variabilidade nos tempos de trânsito gastrointestinal é largamente governada pelos tempos de residência no estômago e válvula ileocecal. No entanto, ao passo que o tempo de esvaziamento gástrico depende da ingestão de alimentos e do tipo de forma farmacêutica, o trânsito na válvula ileocecal mostrou total independência em relação a estes fatores. Ficou igualmente evidente que o trânsito no cólon é alvo de grandes variações inter e intraindividuais.

Além disso, os peletes revelaram-se mais previsí- 
veis no tempo de esvaziamento gástrico e possuem um maior tempo de residência no cólon o que nos permite inferir que este tipo de forma farmacêutica oferece vantagens sobre os tradicionais comprimidos para a concepção de formulações de liberação específica no cólon.

\section{O PH DAS VÁRIAS REGIÕES DO TRATO GASTROINTESTINAL}

Durante muito tempo, foi geralmente aceite que os valores de $\mathrm{pH}$ aumentavam gradualmente do estômago ( $\mathrm{pH} 2,0-3,0)$ e intestino delgado ( $\mathrm{pH} 6,5-7,0)$ até o cólon (pH 7,0-8,0) (Davenport, 1971).

Nos últimos 15 anos, o desenvolvimento da tecnologia de radiotelemetria possibilitou a medida in vivo do $\mathrm{pH}$ do trato gastrointestinal e evidenciou significativas diferenças nos valores de $\mathrm{pH}$ anteriores.

No estômago os valores de $\mathrm{pH}$ são muito baixos (Riley, 1993) como resultado da secreção de íons hidrogênio pela mucosa gástrica. Na presença de alimentos pode variar entre 1,5 e 3,0 ao passo que na sua ausência verifica-se um aumento para valores da ordem dos 4,0-5,0 (Van der Mooter, Kinget, 1995).

No intestino delgado e cólon, e em condições fisiológicas normais, estes valores deverão ser maiores. A medição do valor de $\mathrm{pH}$ nestas regiões em 66 indivíduos saudáveis revelou valores médios de 6,6 no intestino delgado proximal; 7,5 no intestino delgado distal; 6,4 no cego e cólon direito e 7,1 no cólon esquerdo e reto (Evans et al., 1988)

Estes resultados estão de acordo com os descritos por outros autores (Steed et al., 1989) que registaram valores de $7,5 \pm 0,5$ no íleo; $6,4 \pm 0,6$ à entrada do cólon; $6,6 \pm 0,8$ no cólon transversal e 7,0 $\pm 0,7$ no cólon descendente.

$\mathrm{O}$ aumento em várias unidades do $\mathrm{pH}$ entre o estômago e a região proximal do intestino delgado deve-se à neutralização do conteúdo gástrico pelas secreções pancreáticas alcalinas. Adicionalmente, a secreção de bicarbonato por parte da mucosa do intestino delgado, vai contribuir para um contínuo aumento do $\mathrm{pH}$ ao longo desta região, atingindo o seu valor máximo no íleo. À chegada ao cólon, o conteúdo intestinal neutro constituído, entre outros compostos, por polissacarídeos é fermentado pelas bactérias colónicas, o que origina ácidos graxos de cadeia curta e íons hidrogênio, resultando numa diminuição do valor de $\mathrm{pH}$. Este processo de fermentação e a sua contribuição para o decréscimo do $\mathrm{pH}$, vai diminuindo ao longo das restantes regiões do cólon devido, simultaneamente, à menor disponibilidade de substrato e a uma menor velocidade de crescimento bacteriano (Vandamme et al., 2001; Watts e Illum, 1997). Paralelamente, o metabolismo bacteriano de proteínas, aminoácidos e especialmente ureia, conduz à produção de amônia o que poderá contribuir para um aumento do $\mathrm{pH}$ do cólon. Este efeito é mais sentido, nas porções distais já que nas regiões proximais, o pH baixo tende a inibir a ação das enzimas proteolíticas (Watts, Illum, 1997). No entanto, a contribuição do metabolismo proteíco parece ser pouco relevante perante o papel da produção de ácidos graxos de cadeia curta e da secreção de bicarbonato pela mucosa intestinal (Nugent, Rampton, Evans, 2001).

A ingestão de fibras e açúcares não absorvíveis como a lactulose, pode provocar uma diminuição do $\mathrm{pH}$ do cólon devido ao seu efeito na produção de ácidos graxos de cadeia curta (Pye, Crompton, Evans, 1987). No entanto, teoricamente, este efeito pode ser anulado pelo papel que estes compostos presumivelmente exercem na redução do trânsito intestinal.

O reduzido tempo de trânsito pode produzir, quer um aumento do $\mathrm{pH}$ luminal devido ao menor tempo disponível para que ocorram os processo fermentativos, quer uma redução do mesmo se considerarmos, que este facto contribuirá para que as bactérias do cólon produzam mais lactato.

\section{A MICROFLORA DO CÓLON E ENZIMAS}

O cólon é colonizado por um elevado número de microorganismos anaeróbios e anaeróbios facultativos: existem cerca de 400 espécies bacterianas identificadas e muitas outras em vias de identificação o que corresponde a um número de $10^{11}-10^{12}$ microorganismos por grama de conteúdo intestinal (Van Der Mooter, Kinget, 1995; Yang, Chu, Fix, 2002). Os Bacteroides fecalis e bifidobactérias são os predominantes, ao passo que Clostridia, enterobactéria e lactobacilos anaeróbios são comparativamente menos significativos (Steed, Wilson, Washington, 1989; Faigle, 1993; Yang, Chu, Fix, 2002). A microflora gastrointestinal do homem encontra-se exemplificada na Tabela 1.

Em condições fisiológicas normais, estas bactérias não se encontram no estômago, dadas as suas condições de acidez (Haeberlin, Friend, 1992; Faigle, 1993), e em muita baixa extensão ao longo do intestino delgado. O número de microorganismos aumenta gradualmente, ao longo do intestino delgado e encontra a sua expressão máxima em torno da válvula ileocecal (Faigle, 1993). No próprio cólon a velocidade de crescimento dos microorganismos é máxima nas suas regiões proximais, na medida em que aí a concentração de fontes energéticas é superior (Steed, Wilson, Washington, 1989; Watts, Illum, 1997; Vandamme et al., 2001). 
TABELA I - A microflora gastrointestinal no homem. Adaptado de Van Der Mooter and Kinget, 1994

\begin{tabular}{|c|c|c|c|c|}
\hline & Estômago & Jejuno & Íleo & Fezes \\
\hline Número total de bactérias & $0-10^{3}$ & $0-10^{5}$ & $10^{3}-10^{7}$ & $10^{10}-10^{12}$ \\
\hline \multicolumn{5}{|l|}{$\begin{array}{l}\text { Bactérias anaeróbicas ou } \\
\text { anaeróbicas facultativas }\end{array}$} \\
\hline Enterobacteria & $0-10^{2}$ & $0-10^{3}$ & $10^{2}-10^{6}$ & $10^{4}-10^{10}$ \\
\hline Streptococos & $0-10^{3}$ & $0-10^{4}$ & $10^{2}-10^{6}$ & $10^{5}-10^{10}$ \\
\hline Staphylococos & $0-10^{2}$ & $0-10^{3}$ & $10^{2}-10^{5}$ & $10^{4}-10^{7}$ \\
\hline Lactobacilos & $0-10^{3}$ & $0-10^{4}$ & $10^{2}-10^{5}$ & $10^{6}-10^{10}$ \\
\hline Fungos & $0-10^{2}$ & $0-10^{2}$ & $10^{2}-10^{3}$ & $10^{2}-10^{6}$ \\
\hline \multicolumn{5}{|l|}{ Bactérias anaeróbicas } \\
\hline Bacteroides & Raro & $0-10^{2}$ & $10^{3}-10^{7}$ & $10^{10}-10^{12}$ \\
\hline Bifidobacteria & Raro & $1-10^{3}$ & $10^{3}-10^{5}$ & $10^{8}-10^{12}$ \\
\hline Cocos gram-positivos & Raro & $0-10^{3}$ & $10^{2}-10^{5}$ & $10^{8}-10^{11}$ \\
\hline Clostridia & Raro & Raro & $10^{2}-10^{4}$ & $10^{6}-10^{11}$ \\
\hline Eubacteria & Raro & Raro & Raro & $10^{9}-10^{12}$ \\
\hline
\end{tabular}

A flora intestinal obtém a energia para as suas funções celulares através da fermentação de substratos que não foram digeridos no intestino delgado: di e trissacarídeos como a lactulose, celobiose, rafinose e estaquiose; resíduos de die polissacarídeos parcialmente absorvidos como a lactose e amido; e polissacarídeos de natureza endógena como os mucopolissacídeos (Rubinstein, Sintov, 1992). Para isso, possui um vasto espetro de enzimas que catalisam várias reações metabólicas, sobretudo glucosidases $(\alpha-D$ glucosidases e $\alpha$-D-galactosidases, $\beta$-D glucosidases, $\beta$-D galactosidase, $\beta$-D glucuronidase), polissacaridases (amilases, pectinases, xilanases, condroitina liase) mas também esterases e amidases. O resultado desse processo de fermentação é a produção de ácidos graxos de cadeia curta (ácido acético, propiônico e butírico) e gases como o metano, dióxido de carbono e hidrogênio. Dado o leque de reações que estas enzimas podem catalisar, não é de estranhar, que alguns fármacos, uma vez no cólon, lhes possam servir de substrato (Tabela 3 ). O resultado dessas reações pode ser a redução ou otimização da biodisponibilidade sistêmica do fármaco bem como a ativação de um prófármaco. Nalguns casos, pode conduzir a efeitos toxicológicos, como é o caso do metronidazole que sofre uma nitroredução pelas enzimas do cólon dando origem a metabolitos tóxicos (Faigle, 1993).

As proteínas, aminoácidos e uréia podem, igualmente, servir de nutrientes para a flora intestinal através das peptidases, que promovem a desaminação destes substratos com formação de amônia.

No lúmen do cólon, para além da hidrólise, o outro processo metabólico conduzido em condições anaeróbias é a redução, por oposição às enzimas hepáticas que ten- dem a oxidar os seus substratos (Faigle, 1993). Como exemplo de enzimas redutoras encontramos as nitroredutases, azoredutases, $N$-óxidos redutases, sulfóxido reductases e hidrogenases.

A microflora do cólon e as suas fontes nutricionais são qualitativamente similares de um indivíduo para outro, podendo contudo, existir diferenças quantitativas (Vandamme et al., 2001). Essas diferenças devem-se a fatores como a idade, patologias gastrointestinais, administração de fármacos (em particular antibióticos) e fermentação de resíduos de alimentos (Vandamme et al., 2001).

Contudo, a capacidade metabólica do cólon não se restringe à da microflora e enzimas que o colonizam. $\mathrm{Na}$ mucosa do cólon, mais precisamente nos colonócitos, e à semelhança do que ocorre no intestino delgado, existem enzimas com funções metabólicas de natureza oxidativa, hidrolítica e de conjugação (Faigle, 1993). No entanto, dadas as diferenças enormes na área destas duas regiões do trato gastrointestinal, não é de admirar que a capacidade metabólica da mucosa do cólon seja comparativamente inferior.

\section{A CAPACIDADE DE ABSORÇÃO DO CÓLON}

Apesar da via oral ser a principal via de administração de fármacos e, por sua vez, o trato gastrointestinal constituir o local por excelência de absorção de substâncias ativas, são muitas as barreiras que este oferece à absorção. Entre elas, encontramos flutuações de pH, atividade enzimática intensa e a presença de sais biliares que, de uma maneira geral, podem contribuir quer para a destruição quer para a complexação das substâncias ativas 
(Mrsny, 1992a, b). Neste sentido, muitos fármacos tem tendência para ser absorvidos em áreas específicas do trato gastrointestinal devido às características físico-químicas do próprio fármaco (como é o caso da baixa permeabilidade ou solubilidade e instabilidade química) e propriedades do trato gastrointestinal, como por exemplo, interação com os conteúdos do cólon e degradação pelos microoganismos do cólon (Rouge, Buri, Doelker,1996).

O exemplo típico são as proteínas e peptídeos que são instáveis nas porções mais elevadas do trato gastrointestinal, devido, quer ao $\mathrm{pH}$ ácido do estômago, quer à atividade das peptidases no intestino delgado (Rubinstein et al.,1997; Saffran, 1992). Para além disso, possuem um rápido trânsito no intestino delgado e um extenso efeito de primeira passagem, quer pela membrana de absorção, quer pelo fígado (Watts, Illum, 1997). Neste sentido, o cólon tem sido considerado um local interessante para a liberação destes compostos, dado que constitui um ambiente menos hostil no que diz respeito à atividade enzimática. Contudo, não basta que uma dada substância seja estável nas condições do local de absorção: a relativamente baixa atividade enzimática no lúmen do cólon não nos oferece garantias de que estes compostos sejam, efetivamente absorvidos. Na realidade, a baixa permeabilidade intrínseca de proteínas e peptídeos através do epitélio intestinal resulta numa biodisponibilidade inferior a $1 \%$ após a sua administração em sistemas orais de liberação específica no cólon (Yang, Chu, Fix, 2001).

Deste modo, a questão que se coloca é a seguinte: terá o cólon uma capacidade significativa de absorção de substâncias ativas que o torne uma alternativa viável para a liberação específica de fármacos por via oral?

Alguns fatores fisiológicos que influenciam a absorção de fármacos e o metabolismo nas várias regiões do trato gastrointestinal humano estão presentes na Tabela 2 .

Analizando o caso do intestino delgado, onde ocor- rem os principais mecanismos de absorção sistêmica, a existência de uma elevada área de absorção facilita o processo. Pelo contrário, a área disponível no cólon para absorção é significativamente menor e o seu diâmetro é maior, pelo que o contato dos fármacos com o epitélio é consideravelmente menor. Pelas razões expostas, a maioria dos fármacos são absorvidos numa menor extensão no cólon do que no intestino delgado (Rouge, Buri, Doelker, 1996). No entanto, o tempo de residência de fármacos no cólon é muito elevado, o que por si só pode dar lugar a importantes fenômenos de absorção sistêmica. Foi referido que alguns fármacos possuem uma absorção colônica importante após administração oral. Os exemplos típicos são: o diclofenaco, metoprolol, oxprenolol e teofilina (David et al., 1997).

A absorção de fármacos através do cólon pode ser limitada por um número elevado de barreiras: o lúmen, a presença de muco, o espaço existente entre o muco e as células epiteliais e o epitélio, configuram alguns exemplos de barreiras físicas, químicas e metabólicas à absorção não-seletiva de fármacos através do cólon.

Em primeiro lugar, no lúmen do cólon, podem ocorrer interações específicas e não específicas entre fármacos e componentes alimentares da dieta (Mrsny, 1992b). Por exemplo, uma glicoproteína pode interagir especificamente através dos seus resíduos glicosídeos com lecitinas presentes no conteúdo intestinal (Mrsny, $1992 \mathrm{a}, \mathrm{b})$ ou não-especificamente com alginatos não digeridos.

Apesar da menor atividade enzimática presente no cólon, os mecanismos de interação descritos, podem contribuir para um aumento do tempo de permanência dos fármacos no lúmen do cólon e, consequentemente, uma maior susceptibilidade à degradação enzimática. Este é um aspecto que tem suscitado algumas dúvidas relativamente à liberação de proteínas e peptídeos nesta região, uma vez que uma menor atividade enzimática

TABELA II - Fatores fisiológicos que influenciam a absorção de fármacos e o metabolismo nas várias regiões do trato gastrointestinal humano (valores aproximados). Adaptado de Faigle, 1993

\begin{tabular}{lccccc}
\hline Região & $\begin{array}{c}\text { Comprimento } \\
(\mathrm{m})\end{array}$ & $\begin{array}{c}\text { Área } \\
\left(\mathrm{m}^{2}\right)\end{array}$ & $\mathrm{pH}$ & Microorganismos $^{\mathrm{b}}$ & $\begin{array}{c}\text { Tempo de trânsito } \\
(\mathrm{h})\end{array}$ \\
\hline Estômago & 0,2 & 0,1 & $1,5-5,0$ & $\mathrm{~d} \cdot 10^{2}$ & variável \\
Intestino delgado & 7 & 120 & & & 5 \\
Duodeno & 0,3 & 0,1 & 6,6 & $\mathrm{~d} \cdot 10^{2}$ & $\mathrm{~d} \cdot 10^{5}$ \\
Jejuno & 3 & 60 & 6,9 & $\mathrm{~d} \cdot 10^{7}$ & \\
Íleo & 4 & 60 & 7,5 & $\mathrm{e} \cdot 10^{11}$ & $\mathrm{~d} \bullet 48$ \\
Intestino grosso & 1,5 & 0,3 & 8,0 & \\
\hline
\end{tabular}

área de absorção da mucosa; ${ }^{\mathbf{b}}$ Número de microorganismos por grama de contéudo gastrointestinal 
TABELA III - Exemplos de fármacos que são substratos das enzimas da microflora do cólon. Adaptado de Faigle, 1993.

\begin{tabular}{ll}
\hline Substrato & Enzima \\
\hline Ácido caféico & Hidrogenase \\
Cloranfenicol & Nitrorredutase \\
Metronidazole & Nitrorredutase \\
Nicotina- $N$-óxido & N-óxido redutase \\
Nitrazepam & Nitrorredutase \\
Sulfasalazina & Azorredutase \\
Sulfimpirazona & Nitrorredutase \\
\hline
\end{tabular}

no cólon pode ser compensada por um maior tempo de exposição à atividade proteolítica (Rubinstein, et al.,1996). Além disso, o fármaco passará do cólon proximal para a zona distal, onde a presença de bactérias é, ainda, mais significativa e a absorção de água, promove uma solidificação das fezes e uma maior viscosidade do conteúdo luminal, contribuindo para um "aprisionamento" dos fármacos e menor difusão através da mucosa do cólon. A absorção de água que ocorre no lúmen do cólon pode exercer um efeito negativo na absorção de fármacos, na medida que contribui para a diluição dos fármacos mas pode, em certa medida, afetá-la favoravelmente ao facilitar o movimento e mistura e, assim, permitir um melhor contato com a superfície epitelial (Edwards, 1993).

A presença de muco na superfície das células epiteliais constitui uma barreira física à absorção de fármacos pela mucosa do cólon. O trânsito de substâncias activas através do muco é feito por difusão limitada: quanto maior a sua espessura mais tempo levarão as moléculas de fármaco a atravessá-la. No cólon proximal, a presença de células secretoras de muco é mais elevada, não se estranhando, portanto, que a difusão de fármacos nesta região possa estar mais dificultada. Para além disso, o muco, carregado negativamente pode constituir mais um mecanismo de interacção com alguns fármacos, como é o caso das proteínas.

O espaço entre a camada de muco e as células epiteliais pode impedir a absorção de fármacos lipofílicos (Mrsny, 1992a, b). A existência de um gradiente de $\mathrm{pH}$ entre o lúmen e as membranas plasmáticas foi defendido por alguns investigadores que registaram valores de $\mathrm{pH}$ nas células que compõem a mucosa do cólon cerca de uma unidade mais baixo do que no lúmen. Este gradiente pode alterar a solubilidade de alguns fármacos e, por sua vez, a absorção. Para além disso, podem ocorrer significativos processos de destruição enzimática na superfície das cé- lulas epiteliais, especialmente no cólon proximal onde a presença de enzimas é superior.

Provavelmente, a principal barreira à absorção no cólon encontra-se no epitélio onde as células se encontram perfeitamente justapostas constituíndo uma barreira física quase intransponível.

A bicamada lipídica presente no cólon proximal parece mais fluída do que a sua homóloga no cólon distal. Para a atravessar, os fármacos podem seguir dois percursos: uma via transcelular (passagem através dos células intestinais) e uma via paracelular que implica a passagem através dos espaços entre estas células. Estudos realizados em ratos (Taylor, Lynch, Leahy, 1989), sugerem que a absorção paracelular é constante ao longo do intestino delgado e cólon, enquanto que a absorção transcelular se encontra confinada ao intestino delgado. A absorção paracelular é, igualmente, muito baixa no cólon, o que o torna num local mais seletivo de absorção de fármacos do que o intestino delgado (Watts, Illum, 1997). As moléculas de natureza lipofílica são candidatas à via transcelular, que apresenta como principal incoveniente a possibilidade de destruição enzimática no compartimento citoplasmático. A via paracelular permite a passagem de moléculas ionizadas e pequenas (Riley, 1993).

Outra característica interessante do cólon diz respeito à sua elevada capacidade de responder positivamente aos chamados promotores de absorção. Estas moléculas aumentam a permeabilidade do epitélio do cólon promovendo, nomeadamente, a absorção de quantidades terapêuticas significativas de peptídeos, ainda que a biodisponibilidade oral destes compostos permaneça baixa.

Tomita e colaboradores (1988) otimizaram a absorção da via paracelular, de um fármaco pouco solúvel através da adição de promotores de absorção. $\mathrm{O}$ recurso a este tipo de moléculas na administração crônica de fármacos deve ser ponderado na medida que ao aumentarem a permeabilidade de fármacos podem, igualmente, promover a absorção de substâncias indesejáveis, como é o caso de toxinas e agentes patogênicos. À exceção dos sais biliares que sofrem recirculação entero-hepática não é completamente conhecido o destino destas substâncias no organismo ou se podem ou não exercer efeitos tóxicos. Alguns estudos revelaram fenômenos de irritação local e mecanismos de ação irreversíveis (Dodda-Kashi, Grass, Rubas, 1991).

Para as moléculas de fármaco que atravessam com sucesso, todas estas barreiras físicas e enzimáticas, a passagem para a circulação sanguínea ou linfática pode ser problemática (Mrsny, 1992a, b). Um desses problemas é a recirculação entero-hepática para os fármacos que pela primeira vez atingem a circulação sanguínea. Contudo, se a absorção é feita através do sistema linfático este meca- 
nismo não está presente, pelo que resulta numa liberação do fármaco diretamente na circulação sanguínea e por seu turno, uma menor perda de atividade farmacológica.

\section{A DOENÇA INFLAMATÓRIA DO INTESTINO: O SEU IMPACTO NO DESENVOLVIMENTO DE SISTEMAS DE LIBERAÇÃO ESPECÍFICA DE FÁRMACOS NO CÓLON}

\section{Caracterização da doença inflamatória do intestino e seu tratamento}

As doenças inflamatórias do intestino são perturbações crônicas, de etiologia desconhecida, em que o intestino se inflama, provocando muitas vezes cólicas abdominais recorrentes e diarréia.

O grupo de indivíduos afetados encontra-se, sobretudo, na faixa etária dos 15 aos 35 anos e os sintomas mais frequentes são diarreias sanguinolentas, dor abdominal associada a febre, perda de peso e carcinomas.

A doença de Crohn e colite ulcerosa constituem dois tipos distintos de doença inflamatória do intestino. Enquanto que nos pacientes com colite ulcerosa, a perturbação inflamatória crónica está limitada à mucosa do cólon, nos pacientes com doença de Crohn todo o trato gastrointestinal pode ser afetado. Por outro lado, a doença de Crohn afeta, tipicamente, toda a espessura da parede intestinal, incluíndo a zona onde se encontra o sistema linfático.

Para além disso, na colite ulcerosa, os locais de inflamação extendem-se às regiões mais proximais do cólon enquanto que na doença de Crohn o principal local de inflamação é o íleo distal, sendo que em cerca de 30 a 40\% dos casos existe envolvimento do cólon (Both et al., 1983). Com base no que foi dito, um sistema de liberação específica de fármacos é diferente quer se trate do tratamento da doença de Crohn ou da colite ulcerosa.

O tratamento destas patologias é orientado para o controle da inflamação, redução dos sintomas e substituição de qualquer perda de líquidos e/ou nutrientes através de uma dieta adequada.

Os fármacos que fazem parte do plano de tratamento, e que são, simultaneamente, candidatos a pertencer a sistemas de liberação específica no cólon incluem, antiinflamatórios, corticosteróides, antibióticos e imunossupressores. Até ao momento, o tratamento tópico tem tido sucesso apenas com dois tipos de fármacos: ácido 5-aminossalicílico e corticosteróides.

O ácido 5-aminossalicílico, quer na sua forma de prófármaco quer na forma ativa, incorporado em formulações de liberação controlada, enemas e supositórios tem sido o anti-inflamatório mais utilizado para induzir e manter a remissão da patologia no seu estado ligeiro a moderado.

Os corticosteróides têm sido utilizados desde 1955, em tratamentos de curta duração dada a severidade de alguns dos seus efeitos secundários. Nos estados de doença mais severa tem-se recorrido a agentes imunossupressores como é o caso da azatriopina e ciclosporina. $\mathrm{O}$ valor terapêutico de antibióticos como o metronidazole e a ciprofloxacina é incerto.

\section{Impacto da doença nos sistemas de liberação específica de fármacos no cólon, por via oral}

Um dos desafios do desenvolvimento de formulações para o tratamento da doença inflamatória do intestino é o impacto que a própria patologia pode exercer no sistema utilizado para a liberação dos agentes farmacológicos. Historicamente, as investigações que conduziram à concepção destes sistemas foi realizada em modelos animais e voluntários humanos saudáveis pelo que o efeito da patologia nas variáveis tempo, $\mathrm{pH}$ e microflora intestinais pode ter sido subestimado. Uma alteração nestas variáveis resulta numa alteração das características de dissolução e desagregação do sistema e em última instância compromete a sua eficácia.

Estes sistemas vão ser detalhadamente descritos na segunda parte desta revisão. No entanto, de forma a entender os mecanismos pelos quais a doença inflamatória pode afetar um sistema oral de liberação específica de fármacos no cólon, um breve relato da sua constituição e, sobretudo, modo de actuação é apresentado de seguida.

O Asacol ${ }^{\circledR}$ e o Salofalk ${ }^{\circledR}$ são formulações de ácido 5-aminosalicílico revestidas, respectivamente, pelos polímeros Eudragit ${ }^{\circledR} \mathrm{S}$ (que se dissolve a $\mathrm{pH}$ superior a $7,0)$ e Eudragit ${ }^{\circledR}$ L que se dissolve para valores de $\mathrm{pH}$ superiores a 6,0. Estas formulações foram concebidas para liberar o constituinte ativo no íleo terminal e cólon proximal se o $\mathrm{pH}$ luminal nestas regiões for superior a 6 ou 7, por tempo suficiente, para permitir a sua dissolução do polímero de revestimento e, conseqüentemente, a liberação do ácido 5- aminossalicílico.

A sulfasalazina foi o primeiro pró-fármaco do ácido 5-aminossalicílico a ser utilizado, com sucesso, no tratamento da colite ulcerosa. Nesta formulação o componente ativo encontra-se ligado através de um ligação azo a uma molécula de sulfapiridina, sendo liberado mediante a ação de bactérias azoredutases residentes no cólon.

Alguns estudos realizados com estes fármacos provaram que a biodisponibilidade do ácido 5aminossalicílico se encontrava reduzida em pacientes com colite ulcerosa, sobretudo no seu estado ativo, mas 
provavelmente esse efeito não é tão marcado no caso da doença de Crohn.

Esta observação, na nossa opinião, está diretamente relacionada com o resultado de várias investigações que têm vindo a sugerir um $\mathrm{pH}$ mais baixo no cólon de pacientes com colite ulcerosa e doença de Crohn do que em indíviduos saudáveis (Fallingborg et al.,1993; Sasaki et al., 1997; Nugent et al., 2001) e que esta alteração aumenta, progressivamente, com a severidade da doença e com a extensão das suas lesões (Vernia et al., 1988).

O porquê desta redução no valor de $\mathrm{pH}$ não é ainda totalmente claro mas segundo vários autores pode dever-se a uma redução da excreção de bicarbonato (Vernia et al., 1988), um aumento da produção de ácido láctico, ou ainda um aumento da produção de ácidos graxos de cadeia curta (Roediger et al.,1980). No entanto, dado que o valor mínimo de $\mathrm{pH}$ encontrado em alguns estudos referenciados, se encontra abaixo do valor de $\mathrm{pK}_{\mathrm{a}}$ do lactato e dos ácidos graxos de cadeia curta, a explicação mais plausível parece ser a redução da secreção de bicarbonato.

Por outro lado, o baixo $\mathrm{pH}$ encontrado no cólon de alguns pacientes com doença inflamatória do intestino pode ter ainda implicações no metabolismo bacteriano e assim inibir a liberação do ácido 5-aminosalicílico a partir da sulfasalazina. Um estudo in vitro mostrou que um $\mathrm{pH}$ ácido inibe o metabolismo bacteriano de hidratos de carbono, ureia e outros compostos nitrogenados (Wrong, Edmonds, Chadwick, 1981). Além disso, existem diferenças significativas na microflora do cólon de pacientes com doença inflamatória do intestino. Por exemplo, a atividade das glicosidases encontra-se reduzida em pacientes com doença de Crohn relativamente a indivíduos saudáveis (Embden, Lieshout, 1987; Yamni et al., 1992; Canva-Delcambre, et al., 1993). Outra investigação conduzida por Ott et al. (2003) revelou uma redução, respectivamente, de $50 \%$ e $30 \%$ da microflora nos grupos de doentes com doença de Crohn e colite ulcerosa em relação ao grupo controle. Esta diminuição na diversidade da microflora deve-se à perda de bactérias anaeróbias pertencentes às espécies Bacteroides, Eubacterium e Lactobacillus.

Outras alterações inerentes à patologia, embora não tão evidentes quanto as anteriores, podem afetar a absorção de fármacos. Por exemplo, os pacientes que sofrem de doença inflamatória do intestino possuem, tipicamente, uma permeabilidade da mucosa do cólon aumentada, devido à presença de toxinas bacterianas, enterotoxinas e citotoxinas (Mrsny, 1992a). Para além disso, a camada de muco presente em indivíduos com colite ulcerosa é anormalmente fina (Siccardi, Turner, Mrsny, 2005).
Todos estes aspectos devem ser ponderados na concepção e avaliação da eficácia de sistemas utilizados no tratamento da doença inflamatória do intestino.

Para concluir, os resultados de estudos clínicos sugerem que a própria patologia exerce um efeito adverso na eficácia de alguns sistemas de liberação específica de fármacos no cólon. Contudo, novos estudos devem ser conduzidos com intuito de relacionar, com segurança, estes resultados com o pH baixo encontrado no cólon destes pacientes.



FIGURA 1 - Esquema do sistema gastrointestinal. Adaptado de Haeberlin e Friend, 1992.

\section{CONCLUSÕES}

A liberação específica de fármacos no cólon oferece vantagens indiscutíveis quer no tratamento local de patologias quer na absorção sistémica de fármacos instáveis nas regiões superiores do trato gastrointestinal.

Contudo, reconhecer as suas vantagens não diminui as dificuldades em lidar com um órgão que apresenta características anatomofisiológicas tão complexas.

A sua localização na parte final do trato gastrointestinal, associado à elevada variabilidade intra $\mathrm{e}$ interindividual dos tempos de trânsito e valores de $\mathrm{pH}$, oferecem aos investigadores sérias dificuldades. Além disso, o cólon é muito seletivo na absorção de fármacos, apresentando várias barreiras de natureza química, física e metabólica. 
O elevado tempo de residência de fármacos no cólon e a boa resposta a agentes promotores de permeabilidade têm, contudo, contribuído para o reconhecimento de que o cólon tem um elevado potencial como local de liberação de fármacos.

Uma área que requer investigação é a avaliação do comportamento dos sistemas de liberação específica de fármacos em doentes com doença inflamatória do intestino. Existem fortes evidências de que esta patologia pode exercer um impacto negativo nas variáveis tempo, $\mathrm{pH}$ e microflora do cólon. Uma alteração nestas variáveis resultará numa alteração das características de dissolução e desintegração do sistema e em última instância compromete a eficácia dos sistemas de liberação específica de fármacos no cólon.

\section{ABSTRACT}

\section{Colonic drug delivery. I- The colon as a site for drug delivery}

Drug delivery to the colon has become attractive to researchers interested in the treatment of local diseases and for its potential for the delivery of proteins and therapeutic peptides. The treatment of colonic disorders like the inflammatory bowel disease can be improved by the use of systems capable of delivering the appropriate pharmacological agent selectively in the active site of inflammation, because it reduces the oral dose and its systemic side effects. The activity of the peptidases in the colon is very low, which makes possible to such labile molecules like proteins and peptides to be orally administered, without compromising their bioavailability. In the development of these systems it is fundamental to fully understand the colon as a site for drug delivery and, in particular, aspects like transit time, $\mathrm{pH}$ and enzyme activity of the colon, which are the basic mechanisms used to trigger release of a drug in the colon. Another important aspect is the absorptive capacity of the colon. In this context, the long residence time and the presence of some biological and chemical barriers might, respectively, enhance or limit drug absorption. The impact of the active inflammatory bowel disease on the efficacy of the systems used for targeting drugs to the colon might have been underestimated, since this pathology can alter the colonic $\mathrm{pH}$ and the enzyme activity of the colon.

Uniterms: Colon. Gastrointestinal transit. Colonic pH. Colonic microflora. Absorption. Inflammatory bowel disease.

\section{REFERÊNCIAS BIBLIOGRÁFICAS}

ABRAHAMSSON, B.; ALPSTEN, M.; JONSSON, U. E.; LUNDBERG, P. J.; SANDBERG, A.; SUNDGREN, M.; SVENHEDEN, A.; TOLLI, J. Gastro-intestinal transit of a multiple-unit formulation (metoprolol $\mathrm{CR} / \mathrm{ZOK}$ ) and a non-disintegrating tablet with the emphasis on colon. Int. J. Pharm., Amsterdam, v. 140, p. 229-235, 1996.

ADKIN, D.A.; DAVIS, S.S.; SPARROW, R.A.; WILDING, I.R. Colonic transit of different sized tablets in healthy subjects. J. Control. Release, Amsterdam, v. 23, p. 147156, 1993.

ASHFORD, M.; FELL, J. T. Targeting drugs to the colon: delivery systems for oral administration. J. Drug Targeting, London, v. 2, p. 241-258, 1994.

BECHGAARD, H.; CHRISTENSEN, F. N.; DAVIS, S. S.; HARDY, J. G.; TAYLORS, M. J.; WHALLEY, D. R.; WILSON, C. G. Gastrointestinal transit of pellets systems in ileostomy subjects and the effect of density. J. Pharm. Pharmacol., London, v. 37, p. 718-721, 1985.

BORIN, M. T.; KHARE, S.; BEIHN, R. M.; JAY, M. The effect of food on gastrointestinal transit (GI) transit of sustained-release ibuprofen tablets as evaluated by gamma scintigraphy. Pharma. Res., Amsterdam, v. 7, n.3, p.304-307, 1990.

BOTH, H.; TORP-PEDERSEN, K.; KREINER, S.; HENDRIKSEN, B., V. Clinical appearance at diagnosis of ulcerative colitis and Crohn's disease in a regional patient group. Scand. J. Gastroenterol., London, v. 18, p. $987-991,1983$.

CANVA-DELCAMBRE, V.; SOENEN, A.; MIZON, A.; CORTOT, J.; MIZON, J.; COLOMBEL, J.F. L'activite beta-galactosidaseique fecale est diminuee a cours de la maladie de Crohn. Gastroenterol. Clin. Sci., Paris, v. 17, p. 718-722, 1993.

CLARKE, G. M.; NEWTON, J. M.; SHORT, M. B. Comparative gastrointestinal transit of pellets systems of varying density. Int. J. Pharm., Amsterdam, v. 114, p. 1$11,1995$.

CLARKE, G. M.; NEWTON, J. M.; SHORT, M. B. Gastrointestinal transit of pellets of differing size and density. Int. J. Pharm., Amsterdam, v. 100, p. 81-95, 1993. 
CHRISTIAN, P. E.; MOORE, J. G.; SORENSON, J. A.; COLEMAN, R. E.; WELCH, D. M. Effects of meal size and correction technique on gastric emptying time: studies with two tracers and opposed detectors. J. Nucl. Med., London, v. 21, p. 883-885, 1980.

DAVENPORT, H. W. Physiology of the digestive tract. $3^{\text {rd }}$ Ed, Year Book Medical Publisher, New York, 1971.

DAVID, A.; YAGEN, B.; SINTOV, A.; RUBINSTEIN, A. Acrylic polymers for colon-specific drug delivery. STP Pharma Sci., Paris, v. 7, n. 6, p. 546-554, 1997.

DAVIS, S. S.; HARDY, J. G.; FARA, J. W. Transit of pharmaceutical dosage forms through the small intestine. Gut, London. v. 27, p. 886-892, 1986.

DAVIS, S. S. Small intestine transit. In: HARDY, J. G.; DAVIS, S. S.; WILSON, C. G., eds. Drug delivery to the gastrointestinal tract. New York: Ellis Horwood Limited. 1989, p.49-61.

DEVEROUX, J. E.; NEWTON, J. M.; SHORT, M. B. The influence of density on the gastrointestinal transit of pellets. J. Pharm. Pharmacol., London, v. 42, p. 500-501, 1990.

DODDA-KASHI, S.; GRASS, G.M.; RUBAS, W. Oral route of peptide and protein delivery. In: LEE, V.H.L., ed. Peptide and protein drug delivery. New York: MarcelDekker,1991. p.691-738.

EDWARDS, C. A. Anatomical and physiological basis: physiological factors influencing drug absorption. In: BIECK, P. R., ed. Colonic drug absorption and metabolism, Drugs and the Pharmaceutical Sciences, New York: Marcel-Dekker, v. 60, 1993. p. 1-28.

ENCK, P.; MERLIN, V.; ERCKENBRECHT, J.F.; WIENBECK, M. Stress effects on gastrointestinal transit in the rat. Gut, London, v. 30, p. 455-459, 1989.

EMBDEN, J.G.H.R.; VAN LIESHOUT, L.M.C. Increased fecal glycosidases in patients with Crohn's disease. Digestion, London, v. 37, p. 43-50, 1987.

EVANS, D. F.; PYE, G.; BRAMLEY, R.; CLARK, A. G.; DYSON, T. J., HARDCASTLE, J. D. Measurement of gastrointestinal $\mathrm{pH}$ profiles in normal ambulant human subjects. Gut, London, v. 29, p. 1035-1041, 1988.
FAIGLE, J. W. Drug Metabolism in the Colon Wall and Lumen. In: BIECK, P. R., ed. Colonic drug absorption and metabolism, Drugs and the Pharmaceutical Sciences, New York: Marcel-Dekker, v. 60, 1993, p. 29-54.

FALLINGBORG, J.; CHRISTENSEN, L. A.; JACOBSEN, B. A.; RASMUSSEN, S.N. Very low intraluminal colonic pH in patients with active ulcerative colitis. Dig. Dis. Sci., London, v. 38, n. 11, p. 1989-1993, 1993.

FOLLONIER, N.; DOELKER, E. Biopharmaceutical comparison of oral multiple-unit and single-unit sustained-release dosage forms. S.T.P. Pharma Sci., Paris, v. 2, p. 141-158, 1992.

FRIEND, D. R. New oral delivery systems for treatment of inflammatory bowel disease. Adv. Drug Deliv. Rev., Amsterdam, v. 57, p. 247-265, 2004.

GEAR, J.S.S.; BRODIBB, A. J. M.; WARE, A.; MANNY, I. Fiber and bowel transit times. Brit. J. Nutr., London, v.45, p. 77-82, 1981.

GOTO, T.; TANIDA, N.; YOSHINAGA, T.; SATO, S.; BALL, D.J.; WILDING, I.R.; KOBAYASHI, E.; FUJIMURA, A. Pharmaceutical design of a novel colontarget delivery system using two-layer-coated tablets of three different pharmaceutical formulations, supported by clinical evidence in humans. J. Control. Release, Amsterdam, v. 97, p. 31-42, 2004.

GUPTA, V. K.; ASSMUS, M. W.; BECKERT, T. E.; PRICE, J. C. A novel $\mathrm{pH}-$ and time-based multi-unit potential colonic drug delivery system. II. Optimization of multiple response variables. Int. J. Pharm., Amsterdam, v. 213, p. 93-102, 2001.

HAEBERLIN, B.; FRIEND, D. R. Anatomy and physiology of the gastrointestinal tract: implications for colonic drug delivery. In: FRIEND, D. R. ed. Oral colon-specific drug delivery, London, CRC Press, 1992. p. 1-43.

HARDY, J. G. Colonic Transit and Drug Delivery. In: HARDY, J. G.; DAVIS, S. S.; WILSON, C. G., eds. Drug delivery to the gastrointestinal tract. Ed. New York: Ellis Horwood Limited. 1989. p.75-81.

HARDY, J. G. Scintigraphic Tecniques in Studying Colonic Drug Absorption. In: BIECK, P. R., ed. Colonic drug absorption and metabolism, Drugs and the Pharmaceutical Sciences, Ed. New York: MarcelDekker, v. 60, 1993. p. 77-87. 
HARDY, J. G.; DAVIS, S. S.; KHOSLA, R.; ROBERTSON, C. S. Gastrointestinal transit of small tablets in patients with ulcerative colitis. Int. J. Pharm., Amsterdam, v. 48, p. 79-82, 1988.

HARDY, J. G.; WILSON, C. G.; WOOD, E. Drug delivery to the proximal colon. J. Pharm. Pharmacol., London, v. 37, p. 874-877, 1985.

KHAN, M. Z. I.; PREBEG, Z.; KURJAKOVIC, N. A pHdependent colon targeted oral drug delivery system using methacrylic acid copolymers I. Manipulation of drug release using Eudragit ${ }^{\circledR}$ L100-55 and Eudragit ${ }^{\circledR}$ S100 combinations. J. Control. Release, Amsterdam, v. 58, p. 215-222, 1999.

KLOTZ, U.; SCHWAB, M. Topical delivery of therapeutics agents in the treatment of inflammatory bowel disease. Adv. Drug Deliv. Rev., Amsterdam, v. 57, p. 267-279, 2004.

KYROUDIS, A.; MARKANTONIS, S. L.; BECKETT, A. $\mathrm{H}$. The effect of food on the movement of pellets in the gastrointestinal tract. Pharm. Weekbl. Scien. Ed., Amsterdam, v. 11, p. 44-49, 1988.

LAURSEN, L. S.; STOKHOLM, M.; BUKHAVE, K.; RASK-MADSEN, J.; LAURITSEN, K. Disposition of 5 -aminosalicylic acid by olsalazine and three mesalazine preparations in patients with ulcerative colitis: comparison of intraluminal colonic concentrations, serum values, and urinary excretion. Gut, London, v. 31, p. 1271-1276, 1990.

MACLEOD, A. D.; TOZER, T. N. Kinetic perspectives in colon drug delivery. In: FRIEND, D. R. ed. Oral colonspecific drug delivery, London, CRC Press, 1992. p. 85114.

MARDINI, H. AL.; LINDSAY, D. C.; DEIGHTON, C. M.; RECORD, C. O. Effect of polymer coating on fecal recovery of ingested 5-amino salicylic acid in patients with ulcerative colitis. Gut, London, v. 28, p. 1084-1089, 1987.

METCALF,A. M.; PHILLIPS, S. F.;ZINSMEISTER,A. R.;; MCCARTY, R. L.; BEART, R. W.; WOLFF, B.G. Simplified assessment of segmental colonic transit. Gastroenterology, London, v. 92, p. 40-47, 1987.
MRSNY, R. J., Drug absorption in the colon: a critical review. In: FRIEND, D. R. ed. Oral-colon specific drug delivery, London: CRC Press, 1992a. p. 45-84.

MRSNY, R. J. The colon as a site for drug delivery. J. Control. Release, Amsterdam, v. 22, p. 15-34, 1992 b.

NUGENT, S. G.; RAMPTON , D. S.; EVANS, D. F. Intestinal luminal $\mathrm{pH}$ in inflammatory bowel disease: possible determinants and implications for therapy with aminosalicylates and other drugs. Gut, London, v. 48, p. 571-577, 2001.

O’ REILLY, S.; WILSON, C. G.; HARDY, J. G.; The influence of food on the gastric emptying of multiparticulate dosage forms. Int. J. Pharm., Amsterdam, v. 34, p. 213-216, 1987.

OTT, S. J.; MUSFELDT, M.; WENDEROTH, D.F.; HAMPE, J.; BRANT, O.; FÖLSH, U. R.; TIMMIS, K. N.; SCHREIBER, S. Reduction in diversity of the colonic mucosa associated bacterial microflora in patients with active inflammatory bowel disease. Gut, London, v. 53, p. 685-693, 2003.

PHILLIPS, S. F.; QUIGLEY, E.M.M.; KUMAR, D.; KAMATH, P.S. Motility of the ileocecal junction. Gut, London, v.29, p.390-406, 1988.

PRICE, J. M. C.; DAVIS, S. S.; SPARROW, R. A.; WILDING, I. R. The effect of meal composition on the gastro colonic response: implications for drug delivery to the colon. Pharm. Res., Stuttgart, v. 10, n. 5, p. 722-726, 1993.

PYE, G.; CROMPTON, J.; EVANS, D. Effect of dietary fibre on colonic $\mathrm{pH}$ in healthy volunteers. Gut, London, v. 28: A:1366, 1987.

QUIGLEY, E. M. M.; BORODY, T. J.;PHILIPS, S. F.; WIENBECK, M. T. R. L.; HADDAD, A. Motility of the terminal ileum and ileo-cecal junction in healthy humans. Gastroenterology, London, v. 87, p. 857-866, 1984.

READ, N. W.; MANGNALL, Y. F.; TOMLIN, J.; BROWN, N. Non-Invasive Methods for Measuring Gastrointestinal Transit. In: HARDY, J. G.; DAVIS, S. S.; WILSON, C. G., ed. Drug delivery to the gastrointestinal tract. New York: Ellis Horwood Limited. 1989, p.9-25. 
RILEY, S.A. Influence of Disease on Colonic Drug Absorption. In: BIECK, P. R., (Ed.). Colonic drug absorption and metabolism, Drugs and the Pharmaceutical Sciences, New York: Marcel-Dekker, v. 60, 1993. p. 177-195.

ROEDIGER, W. E. The colonic epithelium in ulcerative colitis: an energy deficiency disease? Lancet, London, v. 2, p. 712-715, 1980.

ROUGE, N.; BURI, P.; DOELKER, E. Drug absorption sites in the gastrointestinal tract and dosage forms for sitespecific delivery. Int. J. Pharm., Amsterdam v. 136, p. 117-139, 1996.

RUBINSTEIN, A.; SINTOV, A. Biodegradable polymeric matrices with the potential specificity to the large intestine. In: FRIEND, D. R. ed. Oral colon-specific drug delivery, London, CRC Press, 1992. p. 233-257.

RUBINSTEIN,A.;TIROSH, B.;BALUOM, M.; NASSAR, T.; DAVID, A.; RADAI, R.; GLIKO-KABIR, I.; FRIEDMAN, M. The rationale for peptide drug delivery to the colon and the potential of polymeric carriers as effective tools. J. Control. Release, Amsterdam, v. 46, p. 59-73, 1997.

SAFFRAN, M. Oral colon-specific drug delivery with emphasis in insulin. In: FRIEND, D. R. ed. Oral colon-specific drug delivery, London, CRC Press, 1992. p. 115-142.

SANGALLI, M. E.; MARONI, A; ZEMA, L.; GIORDANO, $\mathrm{F}$; GAZZANIGA, A. In vitro and in vivo evaluation of an oral system for time and/or site-specific drug delivery. $J$. Control. Release, Amsterdam, v. 73, p. 103-110, 2001.

SASAKI, Y.; HADA, R.; NAKAJIMA, H.; FUKUDA, S.; MUNAKATA, A. Improved localizing method of radiopill in measurement of entire gastrointestinal $\mathrm{pH}$ profiles: Colonic luminal $\mathrm{pH}$ in normal subjects and in patients with Cohn's disease. Am. J. Gastroenterology, London, v. 92, p. 114-118, 1997.

SAWADA, T.; KONDO, H.; NAKASHIMA, H.; SAKO, K.; HAYASHI, M. Time-release compression-coated core tablet containing nifedipine for chronopharmacotherapy. Int. J. Pharm., Amsterdam, v. 280, p. 103-111, 2004.

SCHROEDER, K. W.; TREMAINE, W. J.; ILSTRUP, D. M. Coated 5-aminosalicylic acid therapy for mildly to moderately active ulcerative colitis. New Eng. J. Med., London, v. 317, p.1625-1629, 1987
SICCARDI, D; TURNER, J. R.; MRSNY, R. Regulation of intestinal epithelial function: a link between opportunities for macromolecular drug delivery and inflammatory bowel disease. Adv. Drug Deliv. Rev., Amsterdam, v.57, p. 219-235, 2005.

SINHA, S. R.; KUMRIA, R. Binders for colon specific drug delivery: an in vitro evaluation. Int. J. Pharm., Amsterdam, v. 249, p. 23-31, 2002.

SPILLER, R. C.; BROWN, M.L. AND PHILLIPS, S. F. Emptying of terminal ileum in intact humans- Influence of meal residue and ileum motility. Gastroenterology, London, v. 92, p. 724-779, 1987.

STEED, K. P.; HOOPER, G.; VENTURA, P.; MUSA, R.; WILDING, I. R. The in vivo behaviour of a colonic delivery system: a pilot study in man. Int. J. Pharm., Amsterdam, v. 112, p. 199-206, 1994.

STEED, K. P.; WILSON, C. G.; WASHINGTON, N. Drug delivery to the large intestine. In: WILSON, G.; WASHINGTON, N. eds. Physiological pharmaceutics: Biological Barriers to drug absorption. London: Ellis Horwood Limited. 1989. p.91-108.

SUGITO, K.; OGATA, H.; GOTO, H.; KANIWA, N.; TAKAHATA, H.; SAMEJIMA, M. Gastric emptying rate of drug preparations. III. Effects of size of enteric micro-capsules with mean diameters ranging from 0.1 to $1.1 \mathrm{~mm}$ in man. Chem. Pharm. Bull., London, v. 40, p. 3343-3345, 1992.

TAYLOR, D. C.; LYNCH, J.; LEAHY, D. E. Models for intestinal permeability to drugs. In: HARDY, J. G.; DAVIS, S. S.; WILSON, C. G., ed. Drug delivery to the gastrointestinal tract. New York: Ellis Horwood Limited. 1989. p. 133-146.

TOMITA, M.; SHIGA, M.; HAYASHI, M.; AWAZU, S. Enhancement of colonic drug absorption by the paracellular permeation route. Pharm. Res., Amsterdam, v. 5 , n. 6, p. $341-346,1988$

TULEO, C.; ANDRIEUX, C.; BOY, P.; CHAUMEIL, P. C. Gastrointestinal transit of pellets in rats: effect of size and density, Int. J. Pharm., Amsterdam, v. 180, p. 123-131, 1999.

VANDAMME, Th.F.; LENOURRY, A.; CHARRUEAU, C.; CHAUMEIL, J-C. The use of polysaccharides to target drugs to the colon, Carbohydrates Polymers, Amsterdam, v.48, p.219-231, 2001. 
VAN DER BIJL, P. ; VAN EYK, A. D. ; Comparative in vitro permeability of human vaginal, small intestinal and colonic mucosa, Int. J. Pharm. Amsterdam, v.261, p. 147152, 2003.

VAN DER MOOTER, G.; KINGET, R. Oral-colon-specific drug delivery: a review, Drug delivery, London, v. 2, p. 81-93, 1995.

VERNIA, P.; CAPRILLI, R.; LATELLA, G.; BARBETTI, F.; MAGLIOCCA, F. M.; CITTADINI, M. Fecal lactate and ulcerative colitis, Gastroenterology, London, v. 95, p. $1564-1568,1988$.

WATTS, P. J.; ILLUM, L. Colonic drug delivery. Drug Dev. Ind. Pharm., London, v. 23, p. 893-913, 1997.

WILDING, I. R. Scintigraphic evaluation of colonic delivery systems. S.T.P. Pharma Sci., Paris, v.5, n. 1, p. 13-18, 1995.
WRONG, O.; EDMONDS, C.; CHADWICK, V. The large intestine: its role in mammalian nutrition and homeostasis. Lancaster UK:MTP Press, London, p. 133 $155,1981$.

YAMNI, J.; MIZON, C.; CAPON, C; COLOMBEL, J.F.; FOURNET, B.; CORTOT, A.; MIZON, J. Decreased fecal exoglycosidase activities identify a subset of patients with active Crohn's disease. Digestion, London, v. 83, p. 409-415, 1992.

YANG, L.; CHU, J. S.; FIX, J. A. ; Colon-specific drug delivery: new approaches and in vitro/ in vivo evaluation, Int. J. Pharm., Amsterdam, v. 235, p. 1-15, 2002.

Recebido para publicação em 10 de março de 2005. Aceito para publicação em 17 de abril de 2006. 